\title{
Impairment in glycemic control and lipid profile during the Indian festival of Diwali
}

\author{
Nitish Mathur ${ }^{1} \cdot$ Rachita Mathur $^{1}$ • Jairam Rawtani ${ }^{2}$
}

Received: 28 June 2013 / Accepted: 7 August 2015 / Published online: 20 August 2015

(C) Research Society for Study of Diabetes in India 2015

Festive season in India is associated with a marked change in diet of people. It is accompanied by consumption of sweets and fat-rich fried foods. There is a concern that this dietary change can cause significant deterioration in the metabolic profile of patients with T2DM. The effect of this change in diet on blood glucose and lipid profile of patients of T2DM has not been studied $[1,2]$. We studied the effect of expected changes in diet on glycemic control and lipid levels of patients with T2DM around the Hindu festival of Diwali of 2011.

The study was conducted from 12 th October to 11 th November 2011 at the out-patient department of MDM Hospital, Jodhpur. Seventy-two T2DM patients, treated with oral hypoglycemic drugs, were enrolled for the study. Out of them, 67 patients completed follow-up. Their mean age was $60.0 \pm 8.3$ years; male-to-female ratio was 43:24. Mean BMI was $26.14 \pm 2.94 \mathrm{~kg} / \mathrm{m}^{2}$.

The study involved two visits, first within 2 weeks before and second within 2 weeks after Diwali. At each visit, the following biochemical parameters were estimated: fasting and $2 \mathrm{~h}$ post breakfast plasma glucose, lipid profile including total cholesterol, TG, LDL, VLDL, and HDL. At the first visit, height and weight were also measured. The exclusion criteria were patients on insulin therapy and those suffering from renal failure, stroke, cancer, and other conditions affecting diet and

This study was presented as a poster at ENDO 2012 (Houston, TX) and the abstract is present online on the meeting organizer's website.

Nitish Mathur

nitishmathur24@gmail.com

1 S.M.S. Medical College Jaipur, Jaipur, India

2 Department of Biochemistry, Dr S N Medical College Jodhpur, Jodhpur, India weight. The biochemical tests were performed using Bayer Semi-autoanalyzer RA-50. The paired $t$ test was used for comparison of study parameters measured at both the visits and $p<0.05$ was considered significant.

The results of the study show that Diwali is followed by a significant increase in fasting (136.85 \pm 20.43 vs. $154.02 \pm$ $\left.19.16, p=1.82 \times 10^{-14}\right)$ and post-prandial glucose $(185.22 \pm$ 30.66 vs. $\left.207.05 \pm 31.16, p=8.63 \times 10^{-14}\right)$, total cholesterol $\left(198.47 \pm 18.84\right.$ vs. $\left.212.98 \pm 19.06, p=1.69 \times 10^{-15}\right)$, triglycerides $\left(136.37 \pm 25.76\right.$ vs. $\left.153.44 \pm 23.95, p=1.18 \times 10^{-15}\right)$, LDL $\left(130.25 \pm 16.42\right.$ vs. $\left.142.28 \pm 17.50, p=4.56 \times 10^{-13}\right)$, and VLDL $\left(27.27 \pm 5.15\right.$ vs. $\left.30.68 \pm 4.79, p=1.18 \times 10^{-15}\right)$ cholesterol. Whereas, HDL was reduced significantly $(40.94 \pm 3.75$ vs. $40.01 \pm 2.78, p=3.57 \times 10^{-4}$ ) after Diwali.

The results of this study show that there is deterioration of lipid and glycemic parameters after festival of Diwali. These findings have clinical implications. While managing T2DM, lifestyle and cultural factors should be considered. The antidiabetic drugs can be adjusted in accordance with the expected dietary change during festivals. Specialized diet counseling can be of help for patients.

$T 2 D M$ type 2 diabetes mellitus, $T G$ triglycerides, $L D L$ lowdensity lipoprotein, $V L D L$ very-low-density lipoprotein, $H D L$ high-density lipoprotein.

\section{References}

1. Gikas A, Sotiropoulos A, Pastromas V, Papazafiropoulou A, Apostolou O, Pappas S. Seasonal variation in fasting glucose and HbAlc in patients with type 2 diabetes. Prim Care Diabetes. 2009;3(2):111-4.

2. Liang WW. Seasonal changes in preprandial glucose, A1C, and blood pressure in diabetic patients. Diabetes Care. 2007;30(10): 2501-2. 